\title{
Study on Apoptosis of Human Hepatoma Cell line HepG-2 Induced by Total Alkaloids in H.littoralis
}

\author{
Ning $\mathrm{CHEN}^{1,2, \mathrm{a}^{*}}$ \\ ${ }^{1}$ Engineering Research Center of Natural Anticancer Drugs, Ministry of Education, \\ Harbin University of Commerce, Harbin 150076, China \\ ${ }^{2}$ Center of Research on Life Science and Environmental Science, \\ Harbin University of Commerce, Harbin 150076, China
}

s195844330@163.com

Keywords: Total Alkaloids in H.littoralis, Human Hepatoma Cell line HepG-2 Cells, Growth inhibition, apoptosis.

\begin{abstract}
The purpose of this study is to investigate the effect of Total Alkaloids in H.littoralis on the induction of apoptosis involved in Human Hepatoma Cell line HepG-2. HepG-2 cells were treated with different concentrations of Alkaloids in H.littoralis at different time. MTT method was used to study Alkaloids in H.littoralis anti-tumor activity. Morphology observation was performed to determine the effects of Alkaloids in H.littoralis on apoptosis of HepG-2 cells. Flow cytometry (FCM) was used to detect the cell apoptosis rate and analyze the protein expression of Fas. The results showed Alkaloids in H.littoralis could inhibit the growth of HepG-2 cells, and the apoptosis morphology for $72 \mathrm{~h}$ treatment was obvious. FCM indicated that the percentage of apoptotic cells increased with the raised concentration and the protein expression of Fas was increased after treated by Alkaloids in H.littoralis for 72h. In conclusion, Alkaloids of H.littoralis could induce HepG-2 cells apoptosis, and the mechanism may be related to death receptor pathway.
\end{abstract}

\section{Introduction}

Plants of the family Amaryllidaceae have a wide distribution through both tropical and sub-tropical regions of the globe and are prominent in southern Africa and Andean South America [1]. These bulbous flowering plants are known for their horticultural and ornamental appeal, as well as their highly valued medicinal properties [2]. The medicinal value of the Amaryllidaceae has been epitomized by the commercialization of the Alzheimer's drug galanthamine, derived chiefly from daffodils (Narcissus pseudonarcissus) and snowdrops (Galanthus nivalis) [3].

$H$. littoralis, a member of the Amaryllidaceae family, mainly have antitumor and antivirus activity [4]. Alkaloids in $H$. littoralis are the main active components [5]. Experimental studies indicated that alkaloids of H.littoralis with significant antitumor activity, but the mechanism underlying its effect is not clearly understood, so this study investigated whether Alkaloids in H.littoralis could induce HepG-2 cells apoptosis, and research the potential mechanism [6, 7].

\section{Materials and Methods}

Main Agent. Total Alkaloids in H.littoralis(TAHL); hydroxycamptothecin (HCPT); RPMI-1640 culture medium (Gibco); FBS (Hangzhou Sijiqing Biological Engineering Materials Co.,Ltd); Pancreatin (Invitrogen); MTT (Sigma); PI (Sigma); DMSO (Sigma); Rabbit Anti-Human Fas and FITC-Goat Anti-Rabbit-IgG (SANTA CRUZ BIOTECHNOLOGY, INC).

Extraction of the Total Alkaloids in H.littoralis. H. littoralis bulbs adding 5 times $1 \%$ sulfuric acid solution(volume rate) soak for $48 \mathrm{~h}$. The extractive solution was filtered and then adjusted $\mathrm{pH}$ to 10 with $\mathrm{NaOH}$. The filtrate was extracted with n-butanol, whichever is butanol layer was evaporated to dryness to obtain the Total Alkaloids in H.littoralis (TAHL). 
Cell Culture. HepG-2 cells were provided by Center of Research and Development on Life Sciences and Environmental Sciences of Harbin University of Commerce. Cells were grown in RPMI-1640 medium containing $10 \%$ heat-inactivated fetal bovine serum at $37^{\circ} \mathrm{C}$ in a humidified atmosphere of $5 \% \mathrm{CO}_{2}$.

MTT Assay. $5 \times 10^{4}$ cells per well were cultured in a 96-well-plate for first 24 hours. Then, they were incubated with different concentrations of TAHL for further 72 hours. After incubation, MTT was dissolved in PBS and added to culture media at a final concentration of $0.5 \mathrm{mg} / \mathrm{ml}$. After incubation at $37^{\circ} \mathrm{C}$ for 4 hours, the media were removed, $150 \mu \mathrm{l}$ DMSO were added to each well. Spectrophotometric absorbance at $570 \mathrm{~nm}$ was read using microplate reader.

Cell Apoptosis Rate Assay. Cells were treated with different concentrations of TAHL in 6-well-plate for $72 \mathrm{~h}$, then centrifuged and rinsed with PBS, fixed in $70 \%$ cold ethanol for $12 \mathrm{~h}$ at $4^{\circ} \mathrm{C}$., then discarded fixation and washed with PBS twice, PI stain was added to stain the sample for 30 min, the sample was measured by FCM, with an excitation wavelength of $488 \mathrm{~nm}$.

Apoptosis Morphology Observation. Cells were treated with different concentrations of TAHL in 6-well-plate for $48 \mathrm{~h}$, then centrifuged and rinsed twice with PBS, fixed in $4 \%$ paraformaldehyde for $30 \mathrm{~min}$ at $4^{\circ} \mathrm{C}$, then discarded fixation and washed with PBS twice, dyed with Hoechst 33258 for 20 min, then discarded dye and washed with PBS twice, and cells were observed using fluorescence microscope.

Effect of TAHL on the Expression of Fas in HepG-2 cells. Cells were planted in 6-well-plate and cultured for $24 \mathrm{~h}$, and then treated with different concentrations of TAHL for $72 \mathrm{~h}$. Cells were centrifuged and rinsed twice with PBS. Added $2 \mathrm{ml}$ paraformalclehyde $(40 \mathrm{~g} / \mathrm{L})$ to fix cells for $40 \mathrm{~min}$, then removed fixed liquid and rinsed with PBS twice; add $1 \mathrm{ml} \mathrm{0.1 \%} \mathrm{TritonX-100} \mathrm{to} \mathrm{punch} \mathrm{cells} \mathrm{for}$ $15 \mathrm{~min}$, then rinsed with PBS; add $1 \mathrm{~mL} 1 \%$ BSA for $1 \mathrm{~h}$, then removed sealing liquid; add mouse-anti-human antibody respectively and incubated for $1 \mathrm{~h}$ at $37^{\circ} \mathrm{C}$, then removed supernatant fluid and rinsed with PBS; Add FITC-anti-mouse antibody and incubated for $30 \mathrm{~min}$ at room temperature, then discard supernatant fluid and add $800 \mu \mathrm{L}$ PBS, cells were measured using FCM.

Statistical Analysis. Statistical analysis Data were expressed as mean \pm standard deviation (SD). Statistical analyses were done by using the ANOVA test to compare the different groups. Probability (P value) of less than 0.05 was considered to be statistically significant.

\section{Results and Discussion}

MTT Assay. MTT result showed that TAHL inhibited the growth of HepG-2 cells in a dose and time dependent manner. The $\mathrm{IC}_{50}$ was $2.30 \mu \mathrm{g} \cdot \mathrm{mL}^{-1}$. As shown in Table 1 and Fig. 1.

Table 1. Inhibition rate of TAHL on HepG-2 cells by MTT assay ( $\bar{x} \pm s, n=6)$.

\begin{tabular}{cccc}
\hline Groups & Concentration $\left(\mu \mathrm{g} \cdot \mathrm{mL}^{-1}\right)$ & OD & IR $(\%)$ \\
\hline & 0 & $1.161 \pm 0.039$ & \\
& 0.25 & $1.035 \pm 0.023^{*}$ & 10.8 \\
TAHL & 0.5 & $0.91 \pm 0.050^{* *}$ & 21.4 \\
& 1 & $0.65 \pm 0.010^{* *}$ & 43.6 \\
& 2 & $0.50 \pm 0.023^{* *}$ & 56.5 \\
HPTC & 4 & $0.47 \pm 0.002^{* *}$ & 59.3 \\
\hline
\end{tabular}

$*$ Compared with control $\mathrm{P}<0.05, * *$ Compared with control $\mathrm{P}<0.01$ 


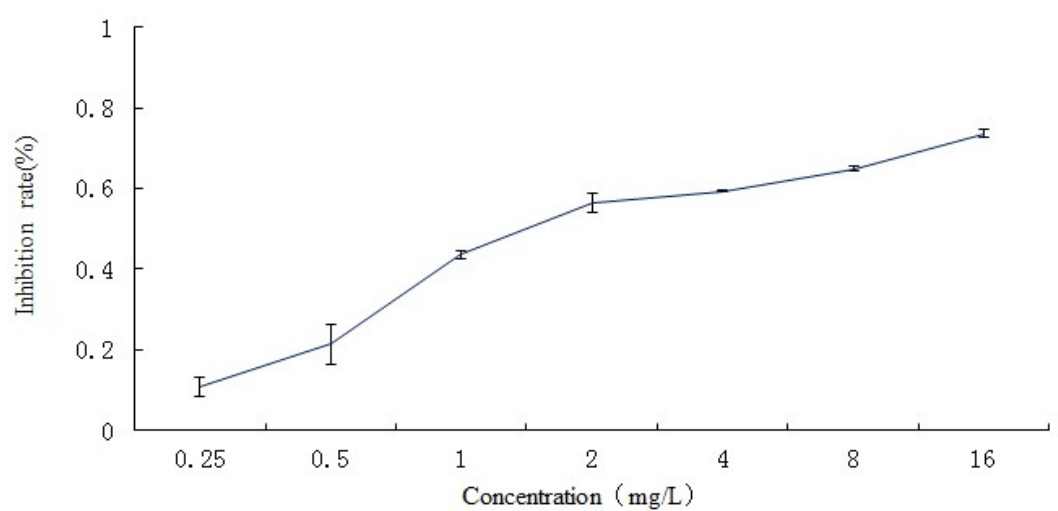

Fig. 1 Effect of TAHL on the proliferation of HepG-2 cells.

Effect of TAHL on Apoptosis Rate Assay. The FCM results showed that the percentage of apoptotic cells increased with the raised concentration of TAHL in a dose-dependent manner. The apoptosis rates were $7.85 \%, 11.05 \%$ and $20.86 \%$ in $2,4,8 \mu \mathrm{g} / \mathrm{mL}$ TAHL group. As shown in Table 2 .

Table 2. Effect of TAHL on the apoptosis rate of HepG-2 cell.

\begin{tabular}{ccc}
\hline Groups & Concentration $\left(\mu \mathrm{g} \cdot \mathrm{mL}^{-1}\right)$ & Protein Content $(\%)$ \\
\hline Control & 0 & $0.67 \pm 0.01$ \\
HPTC & 10 & $4.51 \pm 0.29^{*}$ \\
& 2 & $7.85 \% \pm 0.52^{*}$ \\
TAHL & 4 & $11.05 \% \pm 0.02^{* *}$ \\
& 8 & $20.86 \% \pm 0.91^{* *}$ \\
\hline
\end{tabular}

*Compared with control $P<0.05, * *$ Compared with control $P<0.01$

Apoptosis Morphology Observation. Under inverted fluorescence microscope, cells in control group grew normally, after treated by different concentrations of TAHL for $48 \mathrm{~h}$, a high proportion of cells showed apoptosis-like changes such as being detached and cytoplasmic condensation, leading to cellular swelling, rounding, microvillus disappearing, cytoplasmic condensing, and apoptotic bodies appeared increasingly. As shown in Fig. 2.

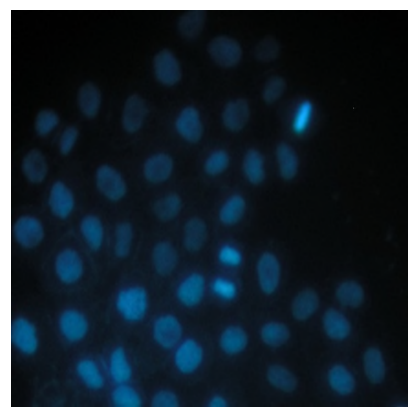

A control

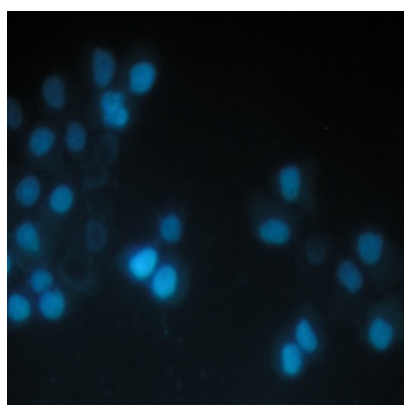

B HTPC

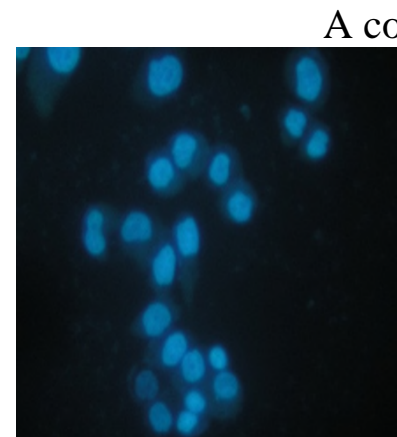

$\mathrm{C} 2 \mu \mathrm{g} \cdot \mathrm{mL}^{-1}$

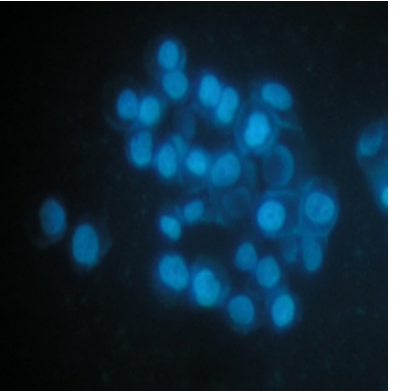

$\mathrm{D} 4 \mu \mathrm{g} \cdot \mathrm{mL}^{-1}$

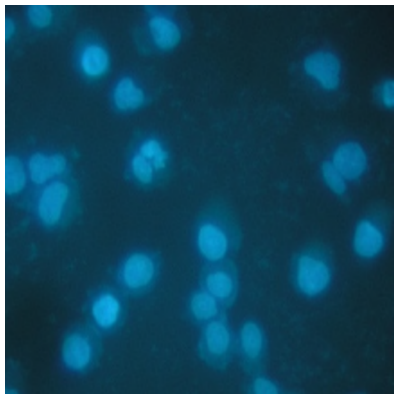

$\mathrm{E} 8 \mu \mathrm{g} \cdot \mathrm{mL}^{-1}$

Fig. 2 Morphological appearance of HepG-2 cells. 
Effect of TAHL on the Expression of Fas in HepG-2 Cells. Flow cytometry showed that after treated with different concentrations of TAHL for $72 \mathrm{~h}$, the expression of Fas was increased, which was statistically significant compared with the control group $(P<0.05)$. As shown in Table 3 and Fig. 3.

Table 3. Effect of TAHL on Fas protein expression in HepG-2 cells.

\begin{tabular}{ccc}
\hline Groups & Dose $\left(\mu \mathrm{g} \cdot \mathrm{mL}^{-1}\right)$ & Fas protein expression $(\%)$ \\
\hline Control & - & $36.2 \pm 0.03$ \\
HCPT & 10 & $84.3 \pm 0.02^{* *}$ \\
& 4 & $50.5 \pm 0.01^{*}$ \\
TAHL & 8 & $66.8 \pm 0.04^{*}$ \\
& 16 & $74.0 \pm 0.03^{*}$ \\
\hline
\end{tabular}

*Compared with control $P<0.05, * *$ Compared with control $P<0.01$

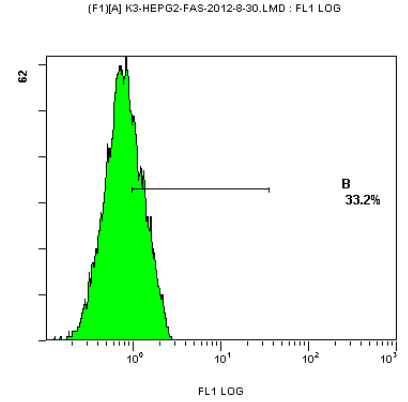

A control

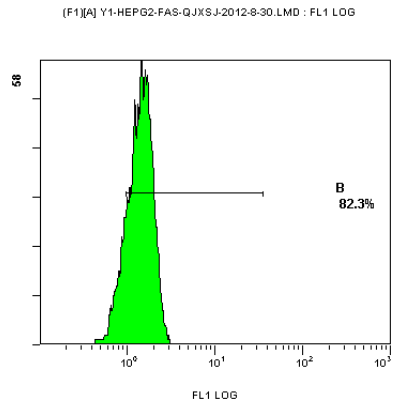

B HTPC

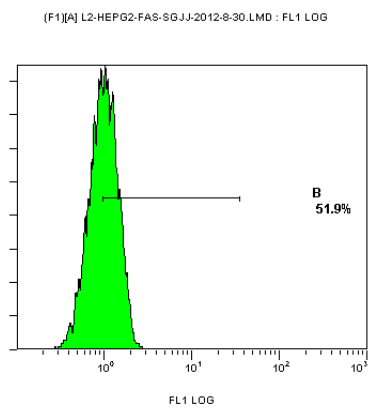

C $4 \mu \mathrm{g} \cdot \mathrm{mL}^{-1}$

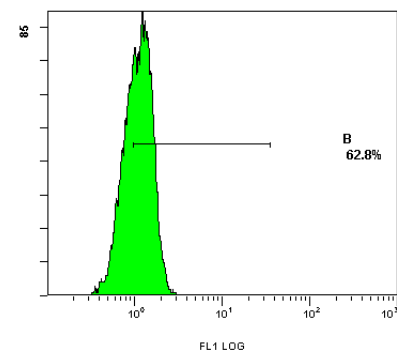

$\mathrm{D} 8 \mu \mathrm{g} \cdot \mathrm{mL}^{-1}$

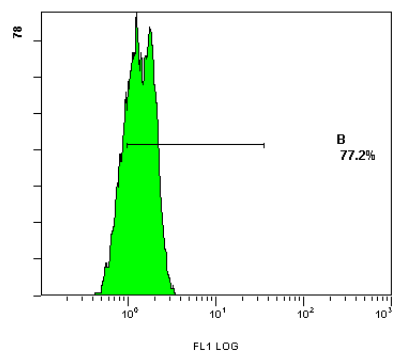

$\mathrm{E} 16 \mu \mathrm{g} \cdot \mathrm{mL}^{-1}$

Fig. 3 Effect of TAHL on Fas protein expression in HepG-2 cells by FCM.

\section{Conclusion}

The occurrence and development of cancer is closely related to cell apoptosis. Indeed, there exist two main pathways of apoptosis: the mitochondrial pathway and the death receptor pathway, also called the extrinsic pathway. Death receptors belong to the tumor necrosis factor (TNF) superfamily of receptor and share in common a distinctive cytoplasmic domain called the death domain. This group of receptors includes FAS and DR3, which interact with Fas-L, DR4, and KILLER/DR5 that binds TNF-related apoptosis-inducing ligand (TRAIL), as well as TNFR1 and DR6. The death receptor pathway of apoptosis has been repeatedly involved in chemotherapy- induced cell death [8].

In conclusion, our data showed that the protein levels of Fas were increased in TAHL-treated cells compared with controls in a dose-dependent manner MTT test showed that TAHL was cytotoxic to HepG-2 cells, and had the inhibitory effects at low concentrations dose, meanwhile FCM result further indicated the induction of apoptosis in HepG-2 cells. The expression of Fas has been demonstrated in a number of solid tumors, the Fas system may play a role in drug-induced apoptosis in some cell types $[9,10]$. Our study inferred that TAHL could induce HepG-2 cells apoptosis via death receptor pathway, but the concrete mechanism deserved further investigation. 


\section{Acknowledgements}

This work was financially supported by the Ministry of Education Key Projects (211045), Doctoral Fund of Ministry of Education Project (20112332110003), Natural Science Foundation of Heilongjiang Province (D201029) and Heilongjiang Provincial Department of Education key technology projects $(12511 \mathrm{z} 011)$.

\section{References}

[1] R. Z. P. Wu, Y. Chen, X. Feng, Pharmacological studies of medicinal plants Amaryllidaceae alkaloids. Chin. Wild. Plant. Resour. 27(5) (2008) 26-31.

[2] L. Z. Lin, S. F. Hu, H. B. Chai, et al. Lycorine alkaloids from Hymenocallis littoralis. Phytochem. 40(4) (1995) 1295-1298.

[3] P. J. Houghton, Y. Ren, M. J. Howes, Acetylcholinesterase inhibitors from plants and fungi. Nat. Prod. Rep. 23(2) (2006) 181-199.

[4] S. H. Ghosal, R. Loehan, A. Y. Kumar, et al. Allmloids of Haemanthus kalbreyeri. Phytochem. 24(8) (1985) 1825-1828.

[5] J. Newmand, G. M. Cragg, K. M. Snader, Natural products as sources of new drugs over the period 1981-2002. Nat. Pord. 66(7) (2003) 1022-1037.

[6] G. R. Pettit, G. R. Pettit, 3rd, R. A. Backhaus, F. E. Boettner, Antineoplastic agents, 294. Variations in the the formation of pancratistatin and related isocarbostyrils in Hymenocallis littoralis. J. Nat. Prod. 58(1) (1995) 37-43.

[7] L. Ingrassia, F. Lefranc, V. Mathieu, et al. Amaryllidaceae isocarbostyril alkaloids and their derivatives as promising antitumor agents. Transl. Oncol. 1(1) (2008) 1-13.

[8] P. Dumont, L. Ingrassia, S. Rouzeau, et al. The Amaryllidaceae Isocarbostyril Narciclasine Induces Apoptosis By Activation of the Death Receptor and/or Mitochondrial Pathways in Cancer Cells But Not in Normal Fibroblasts. Neoplasia, 9(9) (2007) 766-776.

[9] I. N. Lavrik, P. H. Krammer, Regulation of CD95/Fas signaling at the DISC. Cell Death Differ. 19 (2012) 36-41.

[10] N. Gordon, E. S. Kleinerman, Aerosol therapy for the treatment of osteosarcoma lung metastases: targeting the Fas/FasL pathway and rationale for the use of gemcitabine. Aerosol Med Pulm Drug Deliv. 23(4) (2010) 189-196. 